\title{
A dimensão urbano-regional na metropolização contemporânea
}

Rosa Moura. Observatório das Metrópoles-INCT/CNPq e Instituto Paranaense de Desenvolvimento Econômico e Social (Ipardes), Curitiba, Brasil

RESUMO | O estágio contemporâneo da metropolização latino-americana, tendo em vista as relações facilitadas pelos meios de comunicação e informação, particulariza-se por configurações espaciais que transcendem a noção do urbano ou do urbano aglomerado e incorporam a dimensão regional, postulando-se como categorias híbridas. São morfologicamente adensadas e descontínuas, com extenso raio de polarização econômicoinstitucional, confluência de fluxos e sobreposição de escalas. A partir da análise desse processo no Brasil e da identificação do que se optou por denominar "arranjos urbanoregionais", explora-se sua natureza, características, papel na inserção do país na divisão social do trabalho, assim como se apontam possíveis configurações da mesma ordem em outros países da América Latina.

PALAVRAS-CHAVE | Expansão urbana, metropolização, planejamento do desenvolvimento.

ABSTRACT | The contemporary stage of Latin American metropolization, supported by new information and communication technologies, makes evidence spatial configurations that transcend the concept of urban or urban agglomerate and incorporate the regional dimension, as hybrid categories. They are morpholically dense and discontinous, they have a high rate of economic and institutional polarization, a they show a confluence fluxes and a overlay of scales. Based on analysis of this process in Brazil and on the identification of what was denominated "urban-regional arrangements", this paper explores their nature, characteristics, and role in the country's insertion in the social division of labor. It also suggests possible configurations of this same type in other countries of Latin America.

KEY WORDS | Urban expansion, metropolization, development planning. 


\section{Introdução}

No que pode ser considerada "uma nova fase de modernização capitalista", pautada em um novo sistema tecnológico e em um enfoque de governança baseado na liberalização econômica (De Mattos, 2010, p. 3), a metropolização contemporânea deve ser compreendida como uma verdadeira metamorfose do processo de urbanização (Lencioni, 2006), que se reforça em funções superiores em matéria de decisão, direção e gestão - as mais articuladoras das bases econômicas nacionais aos circuitos globais -, concentradas nos principais polos urbanos (Leroy, 2000). Longe de apenas reforçar aglomerações singulares, a metropolização passa a engendrar novas morfologias urbanas, muito mais articuladas e densas, ao mesmo tempo que descontínuas, dispersas, sem limites precisos. Sustenta a ampliação geográfica do processo de acumulação, que fez com que a dispersão dos processos produtivos, filiais e fornecedores das empresas tornasse as aglomerações metropolitanas localizações preferenciais, mais capazes de oferecer as condições requeridas à valorização do capital. "A medida que estas aglomeraciones se fueron imbricando en la dinámica productiva globalizada, una verdadera metamorfosis comenzó a afectar tanto a su organización o funcionamiento, como a su morfología y apariencia” (De Mattos, 2010, p. 3)

Com vistas a colocar em discussão morfologias resultantes de tais transformações no Brasil, neste artigo, volta-se ao conceito e à natureza da categoria “arranjo urbano-regional”. Uma breve abordagem teórico-conceitual situa o referencial adotado para a concepção dessa categoria. Nos itens seguintes, sintetiza-se a metodologia de identificação dos "arranjos urbano-regionais" (AURs) no Brasil e faz-se uma breve caracterização dos mesmos. Compreendendo que a essência do processo que gera um arranjo urbano-regional é a própria essência do modelo de desenvolvimento capitalista e que, portanto, não se restringe ao território brasileiro, os resultados do trabalho estimulam a sugerir, com muita parcimônia, configurações da mesma ordem em outros países da América Latina, arriscandose a exemplos de processos territoriais similares no México, Argentina/Uruguai, Chile, Equador e Venezuela. A confirmação ou descarte dos mesmos fica a espera de investigações específicas.

\section{Configurações territoriais contemporâneas}

No estágio contemporâneo da metropolização, emergem arranjos espaciais em contínua expansão, e inúmeros conceitos são atribuídos ao que se consideram novas formas ou novos conteúdos da cidade e da aglomeração, nos processos de reconfiguração territorial. Para contemplar a expansão e desconfiguração da cidade tradicional monocentral, autores buscam expressões análogas aos distintos papéis que qualificam as morfologias resultantes das relações estabelecidas no ambiente urbano e urbano-regional. Desde o consagrado conceito de metrópole, formas complexas, particularmente decorrentes das novas relações do capital e da reestruturação produtiva, favorecidas por avançadas tecnologias de comunicação, endereçam a uma 
nova noção, a da metrópole transformada, ou até mesmo a do fim da era da metrópole. Pelo que trazem de singular ou de similar, são pertinentes à reflexão sobre os arranjos urbano-regionais, objeto deste trabalho.

Sob a perspectiva da evolução de processos de expansão da ocupação urbana, toma-se como referência a "cidade dispersa", concebida por Monclús (1998; 1999) como resultado de um processo de transformação da cidade compacta, pela criação de novos assentamentos urbanos próximos às grandes cidades ou a grandes vias de comunicação, em um novo tipo de cidade, com uma morfologia difusa, seletiva, mais dispersa e fragmentada. Também a "cidade difusa", caracterizada por Indovina (1991), como uma rede de pequenos e médios centros resultante de uma forma evolutiva do modo de produção, associada à proliferação de pequenas e médias empresas e à consolidação de distritos industriais, sem migração, para alternativas de trabalho em outros setores da economia, dando início à urbanização difusa. Em ambos os casos, as morfologias dessas cidades resultam de uma dispersão e transformação nas práticas sociais e nas relações socioespaciais, análoga à periurbanização. A cidade difusa, mais particularmente, é interpretada não como resultado da "difusão", do urban sprawl ou da dissolução da cidade compacta, mas de um duplo processo de desdensificação dessa cidade e, em maior escala, da densificação do espaço agrário e a partir dele.

Contemplando mudanças na morfologia urbana, apoiadas pelo predomínio do automóvel e das tecnologias de informação, com ampliação territorial do campo de externalidades metropolitanas, e pela localização de empresas e moradias em locais mais distantes, De Mattos (2004) aponta a tendência da "metropolização expandida”, ou seja, expansão territorial metropolitana, fruto de uma periurbanização praticamente incontrolável, mediante a qual o tecido urbano prolifera e se estende. Tal expansão favorece a formação de sistemas produtivos centrais a numerosas atividades localizadas em diversos centros urbanos até então independentes ou autônomos, do entorno da aglomeração metropolitana (similares ao norteamericano urban sprawl).

No âmbito metropolitano, a noção de "megacidade" é desenvolvida por Borja e Castells (1997), que a definem não pelo tamanho, mas como nó com a economia global, como ponto de conexão que, por conta dessa mesma condição, atrai mais e mais população. Davis (2004) sugere que o extremo crescimento populacional em países em desenvolvimento faz emergir novas megacidades e hipercidades, que se envolvem em novas redes, corredores e hierarquias, criando megalópoles urbanoindustriais comparáveis às do mundo desenvolvido. Salienta o crescimento da desigualdade dentro e entre cidades de diferentes tamanhos e especializaçóes.

O conceito de "cidade-região" avança em relação ao de megacidade. Para Scott, Agnew, Soja e Storper (2001), a cidade-região corresponde a um nó espacial articulado globalmente por arranjos de governança (ou formas de articulação do poder), funcionando como plataforma territorial a partir da qual empresas disputam mercados globais. Associada à ideia de cidade-global, a cidade-região global configura estruturas industriais concentradas (sobretudo intensivas em tecnologia), esten- 
dendo o significado do conceito em termos econômicos, políticos e territoriais. Tem como proposição teórica básica que a combinação entre fortes pressões no sentido da metropolização ou aglomeração das atividades econômicas e a globalização da concorrência econômica teria produzido um novo tipo de dinâmica de desenvolvimento ou de crescimento econômico, cujos atores decisivos, as cidadesregiões, passariam a ter uma influência crescente no mundo globalizado. Essas se distinguem do conceito clássico de cidade, considerado muito restrito para o entendimento da crescente interdependência de múltiplas redes de atividades econômicas organizadas em configurações territoriais ampliadas (länder, províncias, municipalidades, áreas metropolitanas etc.).

Esse conceito é adotado, no caso brasileiro, por Lencioni (2003a; 2006), que aprofunda a reflexão teórico-conceitual para o caso da (macro)metrópole paulista. Para a autora, a cidade-região coloca-se como "condição, meio e produto fundamental para a reprodução social nos dias atuais" (Lencioni, 2006, p. 71, grifo no original). Anota que é impossível delimitar a cidade-região, já que se constitui em espaço de fluxos pela interconexão de várias redes. Sua extensão guarda relação com os transportes, que viabilizam os deslocamentos cotidianos, conferindo-lhe "um sentido de conjunto e de unidade" (p.73). Assume a conceituação de Scott et al. (2001), porque ela exprime com mais nitidez que a região constituída pela expansão territorial da metrópole é distinta da "região metropolitana relacionada ao processo de industrialização e urbanização que caracterizaram grande parte do século XX" (Lencioni, 2006, p. 74). Mesmo assim, diferentemente dos mentores do conceito, mantém a dispersão territorial da indústria como o componente indutor dessa configuração.

O território reconfigurado em sua dimensão urbana e regional é tratado por Sassen (2007) na figura da "megarregião". Essa deve ser entendida como uma escala que pode beneficiar-se do fato de que complexas economias necessitam tipos diversos de economias de aglomeração e distintos contextos e escalas geográficas, desde o urbano ao rural, e essa diversidade pode estar incorporada dentro de uma única megazona econômica. Em sua essência, "la mega-región resulta del crecimiento de la población en un contexto geográfico donde ciudades y áreas metropolitanas se mezclan entre sí. Y esto, en efecto, conduce a infraestructuras interregionales, notablemente transporte y electricidad, y varias formas de planificación y coordinación regional, como puede ser observado hoy" (Sassen, 2007, p. 11). A escala megarregional pode conectar os ganhadores e os da retaguarda (rezagados), incluir cidades e áreas tanto globais quanto locais, e pode ser estendida a redes intercidades transfronteiriças, mediante o fortalecimento das conexões de ganhadores e retardatários entre fronteiras.

A noção de "metápole", concebida por Ascher (1995), refere-se a um processo de metropolização "metastática”, em territórios não contíguos e não metropolitanos; de espaços "metropolizados" cujo conjunto ultrapassa e engloba as zonas metropolitanas stricto sensu, desenvolvendo-se de maneira anárquica, não hierarquizada. Contém uma ou várias metrópoles ou como mínimo uma cidade de milhares 
de habitantes, com crescimento radioconcêntrico, linear ou em metástase (como grumos ou agregações em um corpo mais amplo). A estrutura da metápole conjuga cidades existentes, que se alteram por adensamento ou desdensificação, expansão, transformação ou eliminação de bairros degradados, incorporação de novos espaços, sem necessariamente impor contiguidade a um centro de cidade. Configura um conjunto de espaços onde todos ou parte dos habitantes, das atividades econômicas ou dos territórios estão integrados no funcionamento cotidiano (ordinário) de uma metrópole.

As noções até aqui sumarizadas resgatam ideias acerca da "megalópole", definida por Gottman (1970), que se refere a um contínuo urbano de centenas de quilômetros, superando os 20 milhões de habitantes, originado pelo crescimento de uma cidade até o contato com a região de influência de outra cidade. Este crescimento se produz em cada cidade, pela concentração de atividades e população, a custo do espaço circundante, e se encontra favorecido pelos novos meios de comunicação e transporte. Para Castells (2000), é a "reunião articulada de várias áreas metropolitanas no interior de uma mesma unidade funcional e social" (p.60); "exprime o domínio da lei do mercado na ocupação do solo e manifesta, ao mesmo tempo, a concentração técnica e social dos meios de produção e a forma atomizada do consumo, através da dispersão das residências e dos equipamentos no espaço" (p. 62.) Para Lefebvre (1991), a megalopolização ocorre da "implosão/explosão" da cidade, tendo a indústria como atividade central da dinâmica econômica urbana, e da extensão do fenômeno urbano por sobre uma grande parte do território, atravessando as fronteiras nacionais nos grandes países industriais.

Entre as referências teórico-conceituais acerca de novas configurações territoriais, não se pode prescindir da discussão efetivada por Soja (2002) quanto à "pósmetrópole", que sintetiza a ruptura da lógica socioespacial da metrópole baseada numa aglomeração física para um espaço descontínuo, um fenômeno poliédrico, decorrente da desindustrialização e reindustrialização e da desconcentração e reconcentração dos nodos urbanos. A pós-metrópole surge como metáfora da metrópole, ou exópole, que emerge do novo processo de urbanização, decorrente da globalização e reestruturação da economia. Torna-se um espaço que expressa conjuntos de paradoxos criados pelo processo de internacionalização, pois implica em se estender "para fora", do urbano para o global, e em se estender "para dentro", do global para o local-urbano. Para o autor, essas noções dividem, implícita ou explicitamente, a idéia de que "a era da metrópole moderna acabou", o que não significa que a metrópole desapareceu, mas que seu domínio social, cultural, político e econômico, como formas distintas da organização do hábitat humano não está longe de ficar no passado; e que uma nova forma de hábitat está emergindo, não como uma total recolocação, mas como uma nova etapa do desenvolvimento urbano contemporâneo.

As categorias apontadas contrariam correntes que apontam que as novas tecnologias destituiriam de sentido as aglomerações. Scott et al. (2001) justificam como necessária a proximidade, concretizada nas cidades-regióes, dadas as formas pelas 
quais as diferentes atividades econômicas são interconectadas em termos das relações transnacionais ou em rede, entre essas e o resto do mundo. A produtividade e o desempenho são favorecidos pela concentração urbana, que garante a eficiência do sistema econômico e intensifica a criatividade, a aprendizagem e a inovação, tanto pela flexibilidade crescente dos produtores, quanto pelos fluxos de idéias e conhecimento. As redes se encontram nos centros econômicos das maiores cidades-regiões do mundo que, em muitos casos, constituem a base para novas fases de expansão urbana. Para Benko (2002, p. 53), a metrópole facilita mudanças "porque funciona como um grande comutador que permite a organização flexível das cadeias produtivas. Constitui também um tipo de 'seguro', porque permite às firmas enfrentar as mudanças, apoiando-se em vastos mercados de mão-de-obra e de serviços privados e públicos, e, sobretudo, reduz os preços de saída de uma atividade (...)”.

Scott (1994, p. 71), referindo-se à ressurreição dos distritos industriais marshallianos, favorecidos pela ampliação dos mercados internacionais e pela redução dos custos de transporte e desenvolvimento de novas tecnologias da informação, afirma: "Em certos cenários de futurologia urbana, pensou-se que estas tendências anunciavam o fim das grandes aglomerações e uma dispersão generalizada do emprego. [Mesmo assim, várias] "grandes cidades do capitalismo moderno continuaram o seu crescimento e a sua expansão", [dada a tendência] "a intensificar a divisão social do trabalho e, consequentemente, a originar uma concentração renovada noutros subsectores (...). Por conseguinte, o processo de crescimento urbano continua, irregular mas energicamente, a impor o seu império secular à economia espacial do capitalismo."

Fujita, Krugman e Venables (1999), expoentes da economia espacial, também admitem a cidade como o espaço de manifestação dos retornos crescentes, articulando a dimensão urbana à regional, a partir da aglomeração. A concentração de atividades, condicionada mais pela procura de excedentes que pela distância, e sua persistência no tempo geraram diferenças entre lugares, favorecendo as regiões em melhores condições quanto ao fornecimento de insumos, tamanho e acesso a mercados, qualidade do mercado de trabalho e, fundamentalmente, custos de transporte e retornos crescentes de escala. Tais condições orientam a escolha da localização e reforçam o espaço aglomerado.

Storper e Venables (2005, p.22) reiteram a força econômica da cidade e a permanência da aglomeração como centralidade na dinâmica da economia, seja pelos efeitos de encadeamentos para frente e para trás das firmas, incluindo acesso aos mercados, seja pela aglomeração dos trabalhadores e pelas interações localizadas promotoras da inovação tecnológica. O contato "face a face" e o "burburinho" propiciado pelas cidades contribuem para a aglomeração espacial da atividade econômica e das pessoas. Percqueur e Zimmermann (2005) mostram que a relação face a face cria as condições que tornam o espaço suscetível a facilitar o desempenho da coordenação, seja pela proximidade espacial, seja pela transferência de uma relação de um contexto de imersão a outro, seja ainda pela interação direta, quando a relação é estabelecida e, sobretudo, quando é suscetível de compensar uma ausência 
ou insuficiência de proximidade não essencialmente espacial (organizacional ou institucional). No caso da inovação tecnológica, aprendizagem e criatividade, as cidades detêm a condição histórica de locus de inventividade, como apontam Storper e Venables (2005, p. 28), cuja explicação reside no fato de que "a proximidade espacial amplia os fluxos de informação de que os inovadores se utilizam para se comportarem como tal".

É necessário, entretanto, fazer distinção entre abordagens que ressaltam os efeitos dos encadeamentos e externalidades propiciados pela proximidade, daquelas que exaltam a capacidade endógena da escala local, como se por si fosse possível desencadear um virtuoso processo de desenvolvimento. Brandão (2007, p. 51) faz uma crítica a esses tipos de vertentes teóricas simplistas, centradas no endogenismo, posto que desconsideram as determinações profundas do regime social de produção capitalista, "que necessariamente leva às últimas consequências a mercantilização e a penetração recorrente da divisão social do trabalho em todas as possíveis dimensões temporais e escalas espaciais". Escapam, portanto, a essas abordagens, as possibilidades de tratamento adequado das heterogeneidades estruturais dos países subdesenvolvidos.

Em um cenário heterogêneo, é imprescindível pactuar acordos regionais multiescalares e a formulação de políticas integradoras das porções "ganhadoras" e "da retaguarda”, na medida em que essas estão dinamicamente interconectadas; são parte de novas dinâmicas econômicas que combinam a necessidade de áreas dispersas de baixos custos e áreas densas de altos custos. "El objetivo sería evitar una carrera hacia abajo y proveer rutas de desarrollo alternativas a la de privilegiar actividades de punta, (...) como ocurre hoy en los países desarrollados" (Sassen, 2007, p. 11).

É necessário distinguir ainda que, por trás de preocupações dessa ordem, o apogeu de conceitos e novas noçôes de cidades expandidas e conectáveis faz parte de narrativas escalares, que buscam justificar, de maneira coerente e unilateral, as transformações na localização de processos sociopolíticos, articulados por atores ou grupos posicionados em contextos histórico-políticos concretos (corporações transnacionais, redes financeiras e de negócios, e outras forças do mercado) (González, 2008). A escala regional recoloca-se na agenda teórica e política internacional, tanto pela sua compreensão como uma localização estratégica da atividade econômica quanto como uma escala para integração da sociedade civil. Ou seja, as regióes reemergem como novos espaços para desencadeamento de processos econômicos e políticos, para maiores articulações globais. O risco é que essa nova narrativa escalar ou esse novo regionalismo, agora supranacional, pode fazer parte de uma estratégia de desnaturalizar o nacional, como apontam González (2008) e Brandão (2007).

\section{Um novo conceito}

Os arranjos espaciais imersos em um curso genérico, porém guardando singularidades e especificidades, no caso brasileiro, implicam na busca de um conceito próprio. Na pesquisa que se toma por base para este artigo optou-se por "arran- 
jos urbano-regionais" (AURs), como categoria espacial específica pela natureza e processo de formatação (Moura, 2009). ${ }^{1}$ Esses arranjos são unidades concentradoras de população, com relevância econômico-social e infraestrutura científicotecnológica, com elevada densidade urbana, forte articulação regional e extrema complexidade, devido à multiplicidade de fluxos multidirecionais de pessoas, mercadorias, conhecimento e de relações de poder que perpassam seu interior, participando de modo mais integrado, nos âmbitos estadual, nacional e internacional, como principais elos de inserção nos estágios mais avançados da divisão social do trabalho. Caracterizam-se, fundamentalmente, pela multiplicidade escalar, que é elemento ao mesmo tempo potencial e complexo para o desempenho de ações articuladas, práticas de cooperação e união na busca do desenvolvimento e da solução de problemas comuns.

Morfologicamente, esses arranjos absorvem em uma unidade espacial, contínua ou descontínua, centros urbanos e suas áreas intersticiais urbanas e rurais, estreitando relações e dividindo funções com aglomerações vizinhas, alcançando uma escala urbana mais complexa e uma abrangência regional. Sua gênese e processo de expansão advêm tanto da busca por localizações de melhor acessibilidade à atividade econômica quanto da periferização da pobreza urbana, impingida pela lógica do mercado imobiliário. Os AURs são, paradoxalmente, espaços privilegiados à reprodução e à acumulação do capital, ao mesmo tempo em que espaços concentradores de pessoas pobres, de déficits e carências em domicílios e equipamentos urbanos. Em sua composição há desde metrópoles e centros com expressividade funcional até municípios pouco integrados às dinâmicas principais do arranjo. Portanto, são assimétricos quanto às suas características, atributos e elementos constitutivos.

Tais unidades confirmam a importância atual da concentração, a despeito de afirmações de que a reestruturação produtiva, a difusão de novas tecnologias de informação e comunicação e a reorganização espacial do capital lograria reverter centralidades concentradoras. Constata-se que os AURs representam a manifestação espacial de maior complexidade nas dinâmicas territoriais engendradas pela metropolização, como produtos ou possibilidades a esse processo. Concentração, mobilidade, conectividade e proximidade agem como elementos essenciais em sua configuração e são inerentes à dinâmica produtiva em sua dimensão urbano-regional. Os arranjos identificados no Brasil correspondem às porções mais concentradoras e dinâmicas dos respectivos estados/regiões - a maioria dentro da própria "região concentrada" do Sul/Sudeste brasileiro, conforme Santos e Silveira (2001) -, que sustentam a divisão social do trabalho em sua perspectiva hegemônica.

A criação das externalidades que privilegiam os AURs decorre de e envolve apenas municípios ou partes de seu território que já detêm um mínimo de condições técnicas, científicas, institucionais e culturais capazes de contribuir no processo inovador (Benko \& Lipietz, 1994). Os espaços melhor dotados de vantagens comparativas e favorecidos pela proximidade qualificam-se para a atração e sustentação

1 A pesquisa foi desenvolvida no processo de doutoramento da autora e se encontra disponível em: http://www. ipardes.pr.gov.br/biblioteca/docs/Rosa_Moura_doutorado.pdf 
de atividades e investimentos, portanto para a acumulação e reprodução do capital, passando a condicionar a organização da base produtiva. Os municípios ou partes do território de alguns deles, não dotados dessas condições e com pouca capacidade de articulação para conseguirem um salto de qualidade, permanecem à mercê das sobras do processo ou completamente à sua margem. Tais resultados demonstram a presença não homogênea da técnica, da informação, da comunicação, entre outros fatores, na organização do arranjo. Daí, a diversidade produtiva e a diversificação social se restringem às porções centrais dos arranjos, que estabelecem relações verticais com outras aglomerações e centros da região/país/mundo, sem inserir a totalidade do conjunto na mesma dinâmica.

Alguns conceitos apontados pela literatura internacional, anteriormente abordados, referem-se a morfologias que transcendem espacialmente o âmbito urbano compacto ou disperso, seja sob perspectiva da forma seja pela densidade das relações econômico-sociais. Entretanto, o conteúdo desses conceitos não se mostrou adequado à gênese, à natureza e às especificidades dos AURs identificados, seja por resultarem de processos induzidos que não se reproduziram no Brasil na mesma intensidade; seja por exacerbarem a condição metropolitana em suas mais variadas transformações, por ora restrita no País a partes de algumas centralidades principais; seja ainda por tratarem de configurações resultantes de efeitos de tecnologias e infraestruturas tampouco disponíveis; ou por não incorporarem a extrema desigualdade que marca as aglomerações brasileiras e, de modo geral, latino-americanas. O fato urbano-regional expresso no caso de São Paulo configura, talvez, no Brasil, o único arranjo para o qual alguns conceitos ou categorias dispostos nessa literatura são pertinentes e, mesmo assim, sob ressalvas.

Assinala-se que a transformação da natureza de algumas cidades, a hibridez da dimensão que assumem - nem urbana, nem regional - e a multiplicidade escalar, movida pelos fluxos e relaçóes, exigem que efetivamente se adote a categoria urbano-regional no plano analítico e na gestão do território. Porém, longe se está de determinadas narrativas, circunscritas territorialmente, que apregoam que o poder aglutinado por esses arranjos e sua desmesurada expansão física poderiam configurar unidades autônomas que prescindem do Estado-Nação, mesmo que dialoguem diretamente com canais globais de decisão.

\section{Identificação dos arranjos urbano-regionais}

A identificação dos arranjos urbano-regionais no Brasil baseou-se numa sequência de procedimentos que incluiu:

a) Resgate de classificações precedentes, construídas com outras finalidades, mas com resultados comparáveis, tendo sido mapeados todos os municípios apontados como integrantes de aglomeração urbana (Instituto de Pesquisa Econômica Aplicada [IPEA], 2002; Castello Branco, 2003; Instituto Brasileiro de Geografia e Estatística [IBGE], 2008) e os inseridos em algum tipo de unidade 
institucionalizada, segundo categorias constitucionais (região metropolitana, região integrada de desenvolvimento ou aglomeração urbana), desde que classificados nos níveis de integração à dinâmica da aglomeração entre médio a muito alto (Ribeiro, 2009);

b) Combinação da análise fatorial com métodos da estatística de autocorrelação espacial, com base no Índice de Moran Local (Local Indicators of Spatial Association - Anselin, 1995). Foram empregados indicadores mais atuais que os considerados nos estudos precedentes - dois expressando concentração (tamanho populacional e da economia) e dois expressando movimento (intensidade dos deslocamentos pendulares, ou fluxos de pessoas para trabalho e/ ou estudo em município que não o de residência, e proporção desses sobre o total de pessoas do município que trabalham e/ou estudam) - e contemplados todos os municípios do Brasil criados até 2000, chegando-se a resultados próximos ao do conjunto mapeado a partir das classificações precedentes;

c) A caracterização da natureza dos arranjos, se singulares ou urbano-regionais, a partir de: análise das informações das centralidades superiores da escala da rede urbana do Brasil, níveis de metrópoles, capitais regionais e centros subregionais, segundo o IBGE (2008), para identificar a conjunção de centros de gestão e distribuidores de funções a uma rede de municípios que extrapola os contornos das aglomerações identificadas; aferição da conectividade interna nos arranjos apontados, com base na rede viária instalada e nos movimentos pendulares da população, favorecidos por essa rede e por sistemas intra e interurbanos de circulação e transporte de passageiros; dimensionamento do grau de polarização funcional e econômica dos centros principais dos arranjos apontados (Ruiz e Pereira, 2008), descartando aqueles com menor alcance ou com influência apenas local; da presença de aglomerações industriais relevantes (AIEs) e exportadoras (AIEX) (Lemos, Moro, Domingues \& Ruiz, 2005; Moro, Lemos, Domingues, Ruiz \& Freitas, 2006), que apontam possíveis transbordamentos espaciais entre municípios contíguos.

A pesquisa identificou nove situações espaciais que se habilitaram ao conceito de arranjo urbano-regional, polarizados por: São Paulo; Rio de Janeiro; Brasília/ Goiânia; Porto Alegre; Curitiba; Belo Horizonte; Salvador; Recife; e, sem um polo definido, o Leste Catarinense (figura 1). Representam as áreas mais dinâmicas da indústria no Brasil, conectadas pelas principais rodovias e, majoritariamente, comandadas pelas principais centralidades da rede urbana, tendo as maiores escalas de polarização, tanto da população como do PIB e os maiores índices de capacidade tecnológica, refletindo uma força polarizadora superior à expressa na geração e apropriação de renda. São unidades que não se restringem a perímetros estaduais nem demarcam limites precisos e o único com polaridade difusa é o arranjo Leste Catarinense. Registra-se a supremacia da extensão da metrópole São Paulo, que polariza o maior conjunto urbano do país (IBGE, 2008). 
FIGURA 1 | Arranjos urbano-regionais, Brasil

ARRANJOS URBANO-REGIONAIS - BRASIL

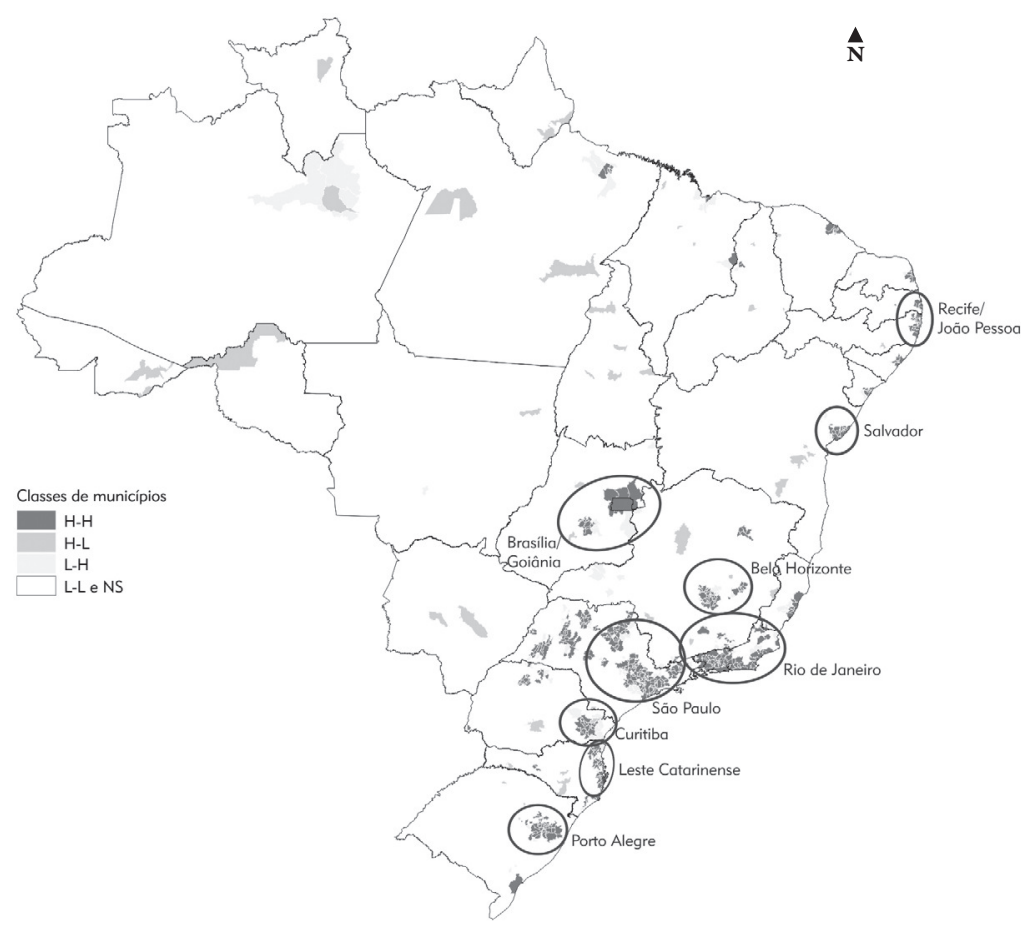

Arranjos singulares pontuam as demais porções do território, mantendo com os AURs relações de complementaridade e/ou subordinação, que consubstanciam a inserção regional na divisão social do trabalho em uma totalidade e expressam os diferentes estágios e as distintas naturezas dessa inserção. Alguns, embora evidenciem relativo grau de abrangência regional da polarização, não se enquadram entre os AURs por ainda se estruturarem em formas simples, expressas na extensão dos polos e conformação de periferias, sem a aglutinação de centros ou aglomeraçóes vizinhas. Essa particularidade se verifica nos casos de Manaus, Belém e Fortaleza.

Observa-se que a indústria nem sempre é o elemento constitutivo determinante de um AUR, que pode prescindir da presença da indústria para realizar fluxos de alta densidade, expandir-se geograficamente e assumir funções de natureza urbano-regional, caso do AUR Brasília/Goiânia. A indústria também nem sempre altera a natureza das relações de um polo ou cria nexos indutores da expansão física e articulação com outros centros e aglomerados, seja por decorrer de uma produção especializada seja por incidir sobre uma localização geográfica na qual 
não ocorrem centros ou aglomerações importantes nas proximidades - casos de Manaus e Fortaleza, com significância industrial e tecnológica, porém não aglutinadores de outras centralidades.

\section{Arranjos urbano-regionais do Brasil}

\section{O arranjo urbano-regional de São Paulo}

Muitos estudos dedicam-se aos resultados morfológicos das novas dinâmicas territoriais no Brasil, em grande parte motivados pela dimensão com que o fenômeno vem se desenvolvendo em torno de São Paulo. Mesmo que se reportem à natureza e aos processos que singularizam essa metrópole expandida, quase sempre buscam relacioná-la a categorias internacionais consagradas, particularmente, cidade-região global, de Scott et al. (2001), ou cidade global (Sassen, 1998), em função de sua dimensão, complexidade e papel na reestruturação do território, consolidando sua posição na escala nacional pela crescente internacionalização de seus fluxos de bens, serviços e informações. Paradoxalmente, as deseconomias de aglomeração, a desigualdade social assentada nos padrões regressivos da distribuição de renda, os impactos socioambientais agudizados pelos volumes populacionais e usos predatórios, e a crescente violência urbana afastam as condições para que essa metrópole ascenda ao patamar de desenvolvimento das cidades globais.

Diniz e Campolina (2007) aceitam sua condição de globalidade apenas no que concerne ao espaço integrado, em um mesmo lugar central, da Região Metropolitana de São Paulo e das microrregiões industrializadas do entorno. Observam a importância da estruturação do sistema viário, datado dos anos 1920, na expansão econômica e populacional dessa região, reforçado pela presença do Rodoanel, na virada do século, que impulsionou a configuração de um arranjo incluindo as microrregióes dentro de um raio de aproximadamente $100 \mathrm{~km}$ do centro do município de São Paulo, formando uma nova configuração industrial contida dentro do entendimento de "campo aglomerativo" proposto por Azzoni (1986). Essa malha viária de qualidade permite a comutação diária de pessoas entre essas cidades, sem romper a primazia de São Paulo.

Já na década de 1920, a região conformada pelo AUR de São Paulo podia ser caracterizada como uma concentração territorial da atividade industrial paulista. Atualmente, está associada à reestruturação produtiva, em uma nova lógica histórica de reprodução do capital, que por mais que tenha alterado as determinações das estratégias e práticas territoriais da indústria, reafirmou a tradicional área industrial do interior paulista, metamorfoseando-a como território metropolitano. No mesmo processo se inclui a região de Santos, porto da cidade de São Paulo, que constitui com esta uma "unidade historicamente indissolúvel" (Lencioni, 2003a, p. 6). Ao contrário de efetivar uma "descentralização metropolitana", o processo reforçou esse centro, que reafirma sua primazia. Além disso, algumas das condiçôes gerais de produção, particularmente aquelas que viabilizam a operacionalização para um 
conjunto de empresas, não estão homogeneamente distribuídas, tornando-se "um limite para a dispersão territorial da indústria e o segredo da formação de um complexo industrial com novas características" (Lencioni, 2003a, p. 5).

Lencioni (2003a, p. 2) mostra que na "metamorfose da forma social da produção industrial se gesta uma metamorfose na forma espacial da cidade". A forma da cidade deixa de emanar da concentração territorial da indústria, pautada na fábrica como forma social de produção industrial, ou na suburbanização, criando as regiôes metropolitanas policêntricas. Nessa nova forma de organização da produção, com a intensificação de redes de proximidade territoriais materiais (circulação) e redes de proximidade relativa imateriais (informação e comunicação), gerando uma metamorfose na morfologia urbana, as dinâmicas territoriais fazem com que se dilua a separação entre cidade e região, como consagrado na literatura, já que nos novos arranjos a própria cidade se torna região (Lencioni, 2006). A autora admite a analogia de cidade-arquipélago, citando Viard (1994), ao caracterizar esse espaço pelas descontinuidades que fragmentam o território, e assume a conceituação de Scott et al. (2001), mais adequada à região constituída pela expansão territorial da metrópole paulista, com a ressalva de que nela é a dispersão territorial da indústria o componente indutor de sua configuração, relacionando-a com a concentração territorial das indústrias inovadoras e mais dinâmicas.

Os dados analisados confirmam essa conclusão. O AUR de São Paulo é fortemente aglutinador de outros grandes e pequenos arranjos vizinhos do próprio Estado, do sul de Minas Gerais e do Estado do Rio de Janeiro, estabelecendo com eles articulação produtiva. A natureza de suas atividades, com elevada incidência da indústria, capacidade tecnológica, firmas exportadoras e a abrangência de sua polarização, atribuem-lhe dimensão urbano-regional e situam-no como a principal formação dessa ordem em território brasileiro.

$\mathrm{Na}$ análise de Ruiz e Pereira (2008), somadas as áreas polarizadas por Campinas e São Paulo tem-se 34 por cento do PIB nacional, 18 por cento da renda agregada, 23 por cento da população em 2005 e a maior renda per capita entre os grandes espaços urbanos que pesquisam (GEUBs), com transbordamento de riqueza e população de São Paulo para Campinas, o que mantém, entre 1996 e 2005, o elevado peso relativo dessas duas grandes aglomerações no conjunto da economia nacional. Considerada a capacidade tecnológica do GEUB de São Paulo e de Campinas, temse 32 por cento da capacidade total e 26 por cento do VTI das empresas exportadoras; agregadas a essas duas aglomerações suas áreas de influência, tem-se 45 por cento da capacidade tecnológica entre os GEUBs brasileiros. Para os Lemos et al. (2005), o papel de "lugar central" de ordem superior da cidade de São Paulo e seu entorno metropolitano lhe confere a função de centro primaz urbano-industrial do território nacional. Mais do que um corredor industrial, a extensão de sua aglomeração revela um espaço industrial contíguo no território regional com níveis avançados de integração e complementaridade produtiva industrial.

Assim, essa cidade-região, dotada de serviços modernos, logística, infraestrutura de transportes, complementaridade produtiva, capacidade de inovação e a mel- 
hor infraestrutura de ciência e tecnologia do país, além de um mercado de trabalho profissional especializado, gera efeitos positivos sobre as decisões locacionais, pois cria externalidades econômicas e socioculturais, reunindo condições de atrair os maiores investimentos em atividades de elevada intensidade de conhecimento, e de exercer forte polarização sobre a economia nacional e internacional.

Outros conceitos são atribuídos a esse arranjo, como macroeixo (São Paulo, 1976), megalópole (Gottman, 1970), macrometrópole (Meyer, Grostein \& Biderman, 2004), complexo metropolitano expandido (Empresa Paulista de Planejamento Metropolitano, S.A. [Emplasa], 1999), configuração em rede de grandes espaços urbanos (Castello Branco, 2003). Esses conceitos e concepções, mesmo que não encerrem uma discussão, por certo confirmam a condição desse arranjo como "um novo fato de caráter metropolitano de dimensão inédita” (Lencioni, 2003a, p. 7), ao menos no Brasil. Lencioni (2003b) sugere que os novos processos e territorialidades no bojo das transformações econômicas recentes, fundamentalmente ligadas à estratégia de cisão territorial da indústria, foram acompanhados de uma forma urbana ainda mais densa e concentrada territorialmente. Ainda que sob diferentes interpretações e denominações, é nítida a convergência quanto ao entendimento de que a dimensão urbana e a dimensão regional são insuficientes para sua compreensão. Assim, há que se concordar e destacar conclusóes de Lencioni (2003a), para quem:

A aparência fenomênica desse novo fato urbano tem recebido diferentes denominações e conceituações. Sejam quais forem essas denominações e conceituações, está claro que estamos diante de um processo novo e de uma nova forma de produção do espaço. (p. 2)

Nesse sentido, pensar a metrópole, a região metropolitana ou o entorno metropolitano é pensar uma região. Mesmo examinando apenas a metrópole, o espectro da região aparece, porque ela em si, não é mais uma cidade isolada, mas uma cidade-região. Uma cidade-região que não se definiu por um planejamento, mas uma cidade que assim se definiu por um processo, por uma lógica histórica que desafia a compreensão de sua dinâmica e, até mesmo, o planejamento urbano. (p. 8)

\section{Outros arranjos urbano-regionais do Brasil}

No caso do Rio de Janeiro, alguns estudos discutem sua inserção no rol de cidadesglobais. Com maior aderência aos processos e morfologias pertinentes aos AURs, Limonad (2007) faz referência à configuração de uma "macro-aglomeração urbano-metropolitana”, com um núcleo forte e a multiplicação de subúrbios em anéis concêntricos, intercalados com áreas de baixa densidade e ocupação, em um crescimento tentacular, que acompanha os eixos de transportes e infraestrutura. De fato, Rio de Janeiro e seu entorno descrevem o segundo maior arranjo de dimensão urbano-regional no Brasil, extrapolando a divisa estadual e estendendo-se em direção a Juiz de Fora, em Minas Gerais. Esse AUR aponta possíveis relações com o de São Paulo, em consequência da articulação pelos possíveis transbordamentos da atividade da aglomeração industrial de Volta Redonda e Barra Mansa, criando 
um elo de relações entre esses dois importantes polos (Davidovich, 2001; Ruiz e Pereira, 2008). Uma maior densificação populacional e econômica das polaridades São Paulo e Rio de Janeiro poderá, num futuro próximo, estender as manchas de extensão de ambas, unindo-as no que virá se constituir o maior e mais complexo arranjo espacial urbano-regional da América do Sul.

Davidovich (2001) enfatiza a elevada concentração, no município do Rio de Janeiro, das atividades comerciais, financeiras, industriais e de serviços da aglomeração metropolitana, cujo acervo político, cultural e tecnológico acumulado quando capital do país constituiu-se no suporte para a instalação do contexto sociotécnico, conforme concepção de Santos (1996), que atribui novos valores a lugares e objetos. Niterói, correspondendo a outro setor dessa aglomeração, também deve sua posição ao legado político-administrativo da função de capital do antigo Estado do Rio de Janeiro, e se reforça com a vigência atual de indicadores positivos de qualidade de vida. A Baixada Fluminense, com grande heterogeneidade interna, tendo como centralidades Duque de Caxias e Nova Iguaçu, representa expressivo potencial de mercado, motivando investimentos na área.

Grandes obras de infraestrutura, como a construção de vias expressas, viadutos extensos, entre outras, vêm constituindo novos eixos de estruturação do espaço metropolitano e vias de ligações mais rápidas entre o aeroporto internacional e setores importantes ao favorecimento da expansão de negócios, particularmente com a Zona Sul, Barra da Tijuca e Riocentro, reforçando internamente a metrópole. Aspecto levantado por Ruiz e Pereira (2008) é que no entorno do Rio de Janeiro não há uma área de expansão tão estruturada e contígua como no eixo São Paulo/ Campinas/São José dos Campos/Sorocaba/Ribeirão Preto. Davidovich (2001) é mais enfática, assinalando que a mancha urbana do Rio de Janeiro se restringe a alguns eixos, tendo a aglomeração metropolitana como centro que se expande em linhas e pontos, diferentemente de São Paulo, que se espraiou em área.

Entre os arranjos urbano-regionais do Sudeste brasileiro, o de Belo Horizonte articula municípios do entorno metropolitano e do Vale do Aço, particularmente o aglomerado Ipatinga/Coronel Fabriciano/Timóteo - aglomeração na qual se encontram empresas exportadoras de grande porte e com participação crescente no valor da exportação de Minas Gerais, ligadas à cadeia produtiva do aço, desde a extração da matéria-prima até o beneficiamento. Essa articulação abrange uma dimensão espacial com centros funcionalmente complementares, tendo Belo Horizonte como polo de inovação, pesquisa e tecnologia, serviços produtivos, serviços pessoais modernos e atividades culturais, e centro da aglomeração com a quarta maior escala industrial de firmas do país. Segundo Ruiz e Pereira (2008), as mudanças recentes na base tecnológica criaram novos vetores de inversões industriais e em serviços, pouco conectados com a base industrial consolidada, ampliando a área mais densa de atividades e população do arranjo. Belo Horizonte polariza todo o Estado de Minas Gerais, exceto porção ao sul e o Triângulo Mineiro, ligadas ao AUR de São Paulo, e áreas de influência compartilhada com o Rio de Janeiro, como Juiz de Fora, ligado ao AUR desse centro (IBGE, 2008). 
Na Região Sul, os AURs identificados já estavam anunciados em estudos que apontam a configuração de um conjunto significativo de aglomerações urbanas com tendências à articulação entre si, desenhando uma mancha semicontínua que se estende no entorno de Curitiba, em tentáculos ao longo das BRs 116 e 277, acompanha o eixo das BRs 376 e 101, em território catarinense, adentra o Vale do Itajaí e atinge, em solo sul-rio-grandense, o entorno de Porto Alegre e serra gaúcha (Instituto Paranaense de Desenvolvimento Econômico e Social [Ipardes), 2000). A espacialização das aglomerações industriais e exportadoras (Lemos et al., 2005; Moro et al., 2006) recobre essas mesmas espacialidades, que se reforçam e usufruem das externalidades peculiares a elas.

A expansão de Porto Alegre e Curitiba apresentam grande associação à idéia de metrópole expandida (De Mattos, 2002; 2005). A aglomeração de Porto Alegre passou por um processo de industrialização antigo, com segmentos especializados expressivos e geograficamente distribuídos, constituindo subcentralidades fortes. No final dos anos 1990, um movimento de espraiamento ou extravasamento das novas localizaçóes industriais ofereceu indícios de retomada do processo de concentração industrial, num processo de incorporação de territórios do entorno metropolitano de Porto Alegre ao espaço econômico regional, denominado "área de expansão metropolitana ou zona perimetropolitana” (Alonso, 2004). Espraiamento que beneficia e articula a aglomeração metropolitana à aglomeração urbana de Caxias do Sul, além de incluir outras centralidades vizinhas, reforçando a hipótese da configuração dos eixos de expansão da região também em um vetor a oeste do seu território, na direção de Lajeado/Estrela/Teutônia e de Santa Cruz do Sul/ Venâncio Aires (Ipardes, 2000).

As mudanças em Curitiba se devem, mormente, a um processo de desconcentração ou de expansão física da área dinâmica dos principais distritos industriais metropolitanos (Curitiba e Araucária), estruturados nos anos 1970, em direção a municípios vizinhos da própria aglomeração ou do entorno mais distante (Moura, 2009). A participação de Ponta Grossa e Paranaguá, nesse arranjo, consolida relações históricas e demonstra a especialização funcional de um conjunto que opera articuladamente na inserção do Estado na divisão social do trabalho, confirmando os efeitos da proximidade como multiplicadores de sua dinâmica, sem romper a primazia desempenhada por Curitiba. Constata-se uma forte articulação produtiva entre os AURs de Curitiba e Joinville, ampliando a centralidade do primeiro, com vetores de expansão em direção a Florianópolis.

O nordeste e leste catarinense consolidam uma rede de aglomerações apoiada na localização de fábricas em um processo de industrialização também nascido na época da colonização do Estado (Lins, 2000), compondo morfologias de certa forma difusas, tangenciando o conceito de Indovina (1990). Pautado em segmentos especializados e geograficamente distintos, tal processo estruturou centros urbanos importantes em várias regiões catarinenses. Entre os centros espacialmente articulados, Joinville polariza o segmento da metalmecânica e Blumenau, o segmento têxtil, com os portos de São Francisco do Sul e Itajaí garantindo suporte aos fluxos 
da produção. Esse perfil se consolidou nos anos 1960 e 1970, com fortes transformações, não só no desempenho dos setores como na dinâmica de urbanização do Estado (Cunha, 2001). Embora Joinville tenha se tornado o município mais populoso de Santa Catarina, Florianópolis reforçou sua função político-administrativa, passando a abrigar um relevante sistema de agências governamentais, instituições financeiras, de comunicações e universitárias. Esse conjunto de aglomerações e centros, favorecido ainda pela expansão da atividade turística, vem induzindo o que se chama de um processo de "litoralização" (Siebert, 2009) do Estado e apontando para a expansão da articulação espacial na direção das pequenas aglomerações de Tubarão e Criciúma, na porção sul do litoral catarinense, também ao longo da BR 101 - tendência que seguramente será confirmada quando ocorrer duplicação desse trecho da rodovia. Mesmo que o arranjo do Leste Catarinense exerça nítida articulação espacial entre suas aglomerações, não constitui polaridade específica, sofrendo forte influência de Curitiba.

No Centro-Oeste brasileiro, o eixo Brasília/Anápolis/Goiânia realiza intenso fluxo de relações e reitera movimentos que perpassam unidades da federação. Este eixo guarda em suas origens e história o papel da ação do Estado no processo de ocupação territorial, tanto no que concerne à criação de cidades (Goiânia, nos anos 1930, e Brasília, nos 1960), quanto, mais recentemente, na expansão da moderna agricultura comercial e agrobusiness, que provocaram a urbanização acelerada e uma nova estrutura produtiva na região (Leme, 2003; Haddad, 2010). Esses centros tornaram-se expressão regional e nacional, concentrando funcionalidades urbanas restritas a um número reduzido de núcleos. $\mathrm{O}$ arranjo combina um centro administrativo federal e um entorno formado por ampla economia regional conduzida pelo agronegócio, com pequena presença da indústria. A área polarizada demanda serviços pessoais, produtivos, financeiros e produtos manufaturados dos centros principais. Aglomerações industriais estão ausentes no Centro-Oeste, mesmo assim, o arranjo Brasília-Goiânia possui extensa área de abrangência da polarização, reforçada pela importância da função de gestão do território e comando político nacional, desempenhada por Brasília, o que lhe atribui natureza urbano-regional.

Estudos específicos voltados ao Nordeste do Brasil têm foco na dimensão urbana das aglomeraçóes metropolitanas, infraestrutura econômica dos estados ou projetos regionais, sem se dedicar a leituras quanto a processos de articulação espacial entre centros. Os AURs dessa região demonstraram menor peso industrial, capacidade tecnológica e presença de firmas exportadoras, porém grande aumento de população e geração de riqueza, ao menos do ponto de vista regional (Lemos et al., 2005; Moro et al., 2006; Ruiz \& Pereira, 2008). Tanto Salvador quanto Recife se afirmam como arranjos urbano-regionais, o primeiro circunscrevendo sua abrangência ao próprio Estado da Bahia, morfologicamente extrapolando os limites do aglomerado metropolitano, em direção a Feira de Santana; e o segundo, adentrando o Estado da Paraíba. Prenuncia-se que o adensamento linear/litorâneo a partir de Recife se projete na direção de Maceió, ao sul, e Natal, ao norte. 
CEURE | vOl 38 | No 115 | SEPTIEMBRE 2012 | pp. 5-31

\section{Similaridades em casos latino-americanos}

\section{A comparabilidade com o México}

No âmbito dos países latino-americanos, apenas o México apresenta uma rede urbana e um processo de metropolização comparáveis ao Brasil. A dimensão do país, sua diversidade, heterogeneidade, inserção internamente diferenciada na divisão social do trabalho, condição de desenvolvimento desigual e dinâmicas territoriais descrevem similaridades quanto à configuração de arranjos urbano-regionais. Embora o México tenha atingido o grau de 50 por cento da população vivendo em cidades apenas nos anos 1970, a metropolização teve início na década de 1940, com o impulso industrializador do modelo de substituição de importações. Desde então, foram inúmeros os esforços nos meios acadêmico e governamental, para definir e delimitar "zonas metropolitanas" no país. Em 1940, Unikel, Ruiz e Garza (1978) reconheceram cinco zonas metropolitanas no país; em 2005, o Consejo Nacional de Población (Conapo, 2007) constatou 56 zonas metropolitanas, das quais seis são interunidades federativas. Essas concentram 56 por cento da população total, 79 por cento da população urbana e 75 por cento do produto interno bruto nacional, o que espelha a transformação do perfil demográfico e econômico do México para um caráter predominantemente urbano.

Analisados os critérios da delimitação mais recente das zonas e municípios metropolitanos desse país (Conapo, 2007), concluiu-se que há muita proximidade entre estes e os empregados na delimitação das aglomerações urbanas brasileiras. Em ambos os casos, consideram-se indicadores de população (volume, densidade, movimentos pendulares), ocupação em continuidade e integração funcional. Tais critérios não são capazes de captar a efetiva natureza das relações intrínsecas às unidades identificadas, o que leva a crer que, como no Brasil, um conjunto principal tenha natureza metropolitana, enquanto outro, deva se caracterizar por natureza não metropolitana.

Essas regióes são representativas da diferenciação territorial do modelo de industrialização adotado pelo país, inicialmente centrado em Ciudad de México. A zona metropolitana do Valle do México, onde se situa, tem se destacado historicamente por seu domínio sobre as demais regiões desde a época pré-hispânica. Segundo HiernauxNicolas (1998, p. 101), a "Revolución Mexicana no modificó estas tendencias y la fase de sustitución de importaciones privilegió a la Ciudad de México y, accesoriamente, a Guadalajara y Monterrey con sus nuevas bases de acumulación, con los resultados de concentración y centralización bien conocidos y ampliamente estudiados por los especialistas mexicanos". Tanto a abertura de mercados quanto a postura atrativa a investimentos estrangeiros diretos têm reforçado a primazia de gestão de Ciudad de México e, secundariamente, de Monterrey, inclusive "eclipsando radicalmente Guadalajara" (Hiernaux-Nicolas, 1998, p. 111). Uma primazia já não tão focada na concentração do emprego e da população, mas no fato de sediar grandes empresas e manter o controle financeiro e político do país. Recentralização com desconcentração seria então a tônica da dinâmica atual dessa centralidade, segundo o autor. 
As mudanças na economia mexicana, ocorridas durante os últimos 15 anos, provocaram profundas repercussões na organização do território, nos sistemas sociais e nas economias urbanas, com forte crescimento demográfico e econômico das cidades médias, e modernização da arquitetura e das formas urbanas na maioria das cidades do sistema urbano nacional (Hiernaux-Nicolas, 1999). A reestruturação econômica e das antigas bases industriais das metrópoles atraiu novos complexos comerciais e espaços "pós-modernos", intensificando a segregação de bairros. $\mathrm{O}$ autor associa a transformação progressiva de Ciudad de México à metápole de Ascher (1995), com forte capacidade para incidir no ordenamento da região central do país. Refere-se à cidade reconstruída sobre si mesma, concomitantemente à sua expansão periférica sobre novos territórios, nos quais se instalam segmentos mais pobres. Ambos os processos testemunham a reacomodação socioterritorial de uma metrópole que "busca su lugar en el concierto de las ciudades mundiales, pero que, al mismo tiempo, redibuja sus comunidades y vuelve a tejer las relaciones sociales hacia el interior de su territorio" (Hiernaux-Nicolas, 1999).

Com ênfase nas áreas periurbanas, ou "periferias metropolitanas expandidas" das megacidades, Aguilar (2002) descreve o padrão urbano de Ciudad de México como mais disperso, com a emergência de subcentros, em uma estrutura multinuclear, básica dos territórios metropolitanos. Esta vem adquirindo forma diferente daquela de um passado recente. Para o autor, de compacta, a megacidade assume uma expansão mais policêntrica, criando um padrão associado a redes, com limites e fronteiras dificilmente definíveis, que incorpora progressivamente pequenos povoados e periferias rurais dentro de um sistema metropolitano cada vez mais amplo e complexo.

Entre as nove zonas principais, fortemente condicionadas por processos de concentração e expansão geográfica da atividade econômica, encontram-se configurações espaciais que se assemelham aos AURs do Brasil, aglutinando conjuntos expressivos de zonas metropolitanas e alongando-se em manchas de grande extensão. A principal reúne em continuidade as zonas metropolitanas de grande porte do Valle de México, Puebla/Tlaxcala e Toluca, além de outras zonas de menor porte, como Cuernavaca, Cuautla, Tlaxcala/Apizaco, Tulancingo, Pachuca e Tula, com nítido vetor em direção a Querétaro, a noroeste, e a sudeste, Tehuacán, Orizaba e Córdoba. Conjugam uma região megametropolitana com 12 zonas metropolitanas, 165 autoridades metropolitanas, 3 governos de Estado e 16 delegações (Conapo, 2007). Podem ser considerados ainda os conjuntos formados por Monterrey, Saltillo e Monclova/Frontera, no nordeste mexicano, e Minatitlán, Coatzacoalcos e Acayucán, no Golfo do México. No caso da primeira, Villareal (1998) ressalta as intensas relações entre o empresariado e governos dos estados do norte e nordeste do México com os do Texas, tendo Monterrey uma posição fundamental, firmando uma zona de interdependência econômica. No nível regional, a autora cita o corredor industrial junto às áreas metropolitanas de Saltillo e Ramoz Arizpe (a $85 \mathrm{~km}$ de Monterrey), com a instalação de montadoras que articulam empresas locais com transnacionais. 


\section{Outros casos latino-americanos}

Nos demais países latino-americanos, que também vêm passando por intensa transformação em suas áreas metropolitanas principais (De Mattos, 2002, 2004, 2010; Dematteis, 1998), os sistemas articulados se conformam fundamentalmente nessas áreas, que se caracterizam pela expansão física do território ocupado, densificação dos fluxos de mercadorias, comutação de pessoas e emergência de novas centralidades. Também tendem à conjugação e articulação de unidades aglomeradas e centros das proximidades em arranjos articulados. Esses arranjos estão no foco da implantação de grandes obras de infraestrutura dentro de estratégias de integração produtiva latino-americana, o que supostamente poderia reforçar sua unidade e seu papel na inserção dos respectivos países na divisão social do trabalho.

$\mathrm{Na}$ Argentina, intensifica-se a expansão da metrópole de Buenos Aires, cujo padrão concentrador, que passava por uma desconcentração incipiente nos anos 1970, agudiza-se a partir dos anos 1990. É para essa metrópole que convergem investimentos públicos e privados, além da modernização de serviços e equipamentos, ampliando suas vantagens comparativas e sua capacidade de articulação externa das economias nacional e internacional. A cidade passa por grandes operações urbanísticas, enquanto outras intervenções acontecem em sua aglomeração metropolitana como um todo, alcançando um significado mais modesto, porém crescente. Como nas demais metrópoles latino-americanas, capitais locais e exógenos "parecen ver a ciertas áreas de Buenos Aires como el mercado del capitalismo mundializado, o como 'locus de gestión empresarial y control de la información' de segundo orden en la red jerárquica de las ciudades globales" (Ciccolella, 1998).

Tal fortalecimento da capital federal esvaeceu o crescimento de cidades médias e metrópoles vizinhas, incluindo as de sua maior proximidade, Rosario e Mar del Plata, tal como de Montevidéu, no Uruguai. Mesmo assim, grandes obras de infraestrutura podem refortalecer esses centros e aproximá-los mais à dinâmica presente em Buenos Aires. Dentro do Plano Ferroviário Estratégico desenhado para a Argentina, que pretende o uso de novas tecnologias de circulação, está previsto um trem de alta velocidade entre Buenos Aires, Rosario e Córdoba e outro, já em processo licitatório, ligando Buenos Aires a Mar del Plata (Schweitzer, 2008), em percursos com poucas paradas e curta duração. Além destes, poderá vir a ser fortalecida a ligação Buenos Aires-Montevidéu, na baía do Plata, atualmente servida por sistemas de travessia de passageiros por aerobarco, complementada por ferry para a travessia de passageiros e veículos a partir de Colonia del Sacramento, no Uruguai. Entre as grandes obras de infraestrutura pensadas no âmbito dos projetos que conformam a estratégia internacional de ligação Atlântico-Pacífico, inclui-se uma ponte entre Buenos Aires e Colonia del Sacramento, como alternativa de transporte entre a Região Metropolitana de Buenos Aires, Montevidéu e ligação com o Sul e Sudeste brasileiros (Laurelli, Montaña \& Schweitzer, 1998).

No primeiro caso, os efeitos das infraestruturas sobre o território argentino serão marcantes, podendo confirmar materialmente a configuração (já insinuada) 
de um arranjo urbano-regional polarizado por Buenos Aires. No segundo caso, ainda sob perspectiva de longo prazo, em que pese a existência de dois EstadosNacionais, as relações entre essa metrópole e Montevidéu poderão ser ainda mais intensificadas, com efeitos territoriais transformadores. A presença de escalas nacional e politicamente autônomas, certamente será um complicador na gestão desse espaço, porém pode-se antecipar que os fluxos de pessoas e mercadorias desconsiderarão as fronteiras.

No caso do Chile, inúmeros estudos mostram que a globalização transformou o país mais rapidamente que outros vizinhos. A profunda reestruturação pós-anos 1970 culminou em uma etapa de crescimento econômico sustentado, reindustrialização e terceirização do aparato produtivo, com progressiva recuperação da tendência à concentração metropolitana em Santiago (De Mattos, 1999). A capital chilena não só assumiu o comando do poder econômico como a localização das principais atividades industriais e terciárias. Nesse processo, intensificou-se a suburbanização tanto de atividades produtivas como de população na área metropolitana de Santiago. Fundamentalmente, deu-se a emergência de uma cidade de "cobertura regional, suburbanizada y policéntrica, de límites imprecisos, configurada como archipiélago, cuya dinámica expansiva ha ido incorporando a diversos centros urbanos aledaños y áreas rurales, que han pasado a formar parte de un extenso periurbano" (p.29). Do ponto de vista arquitetônico, surgiu e se consolidou um conjunto de novos artefatos urbanos (shopping malls, grandes centros comerciais, condomínios e bairros fechados, centros empresariais descentralizados etc.), também presentes nas demais aglomerações latino-americanas, fortemente estruturadores e articuladores do novo espaço metropolitano expandido.

Santiago reforça sua primazia regional ao mesmo tempo em que intensifica relações com a região litorânea, mantendo complementaridade com Valparaíso e Viña del Mar, dado o exercício da função portuária pelo primeiro e de serviços complementares pelo segundo, num momento em que a dinâmica importadora/exportadora se faz mais acentuada no país. Tal relação tem grande similaridade com a desenvolvida entre São Paulo e a Baixada Santista, no caso brasileiro. No Chile, essa aproximação é também favorecida por um sistema viário moderno e um sistema de transporte de passageiro de ampla cobertura, que intensifica as trocas cotidianas entre essas regiões e centros, expandindo-se a uma extensão mais ampla e transformando a natureza de suas relações, que assumem uma dimensão urbano-regional.

Respondendo por modos peculiares de inserção do país na divisão social do trabalho, outros AURs poderiam ser apontados na América do Sul. No Equador, duas áreas de intensa dinamicidade podem se traduzir em arranjos espaciais: um na Serra, polarizado por Quito, com vetores a noroeste $(120 \mathrm{~km}$ até Ibarra, com Cayambe e Otavalo como centralidades intermediárias) e a sudeste (com mais intensidade até Ambato, a $140 \mathrm{~km}$ de Quito); outro na costa, ao longo do eixo litorâneo do Pacífico, polarizado por Guayaquil. Na Venezuela, a articulação espacial entre centralidades expressivas no entorno de Caracas, particularmente no eixo da via Panamericana, no sentido Maracay/Valencia, também sugere um arranjo urbano 
regional. Seguramente outros poderão ser identificados no Peru e na Colômbia, motivando estudos complementares sobre sua natureza.

\section{Considerações finais}

No atual contexto econômico latino-americano, tais configurações espaciais peculiarizam um processo de metropolização avançado, no qual a urbanização mantém-se associada, entre outros fatores, à concentração industrial e a movimentos migratórios e pendulares de curta distância. Esse processo reforça e modifica centralidades secundárias, porém mantém inconclusa a ocupação e expansão das áreas metropolitanas principais. Mas a metropolização contemporânea mostra processos e morfologias cada vez mais enredadas e distantes do desenho em sequência de anéis concêntricos a um polo principal - desenho que caracteriza ainda muitas das aglomerações urbanas existentes. Processos e resultados espaciais, em alguns casos, decorrentes da fragmentação de um núcleo metropolitano em múltiplas e novas centralidades, que aparentemente adquirem vida própria, o que remete à metropolização expandida ou dilatada de De Mattos (2004) e à cidade dispersa de Monclús (1998; 1999), ou, dada a natureza da evolução, à cidade difusa de Indovina (1990); mas, vão além destas em termos de abrangência e composição. Matizados por um estreitamento regional das relações pré-existentes intrinsecamente e entre espacialidades, transformadas sob novas dinâmicas, tais processos desencadeiam formas ainda mais complexas, de natureza urbano-regional, algumas consoantes à cidaderegião de Scott et al. (2001), como propõe Lencioni (2006) para São Paulo, ou à metápole de Ascher (1995), conforme Hiernaux-Nicolas (1999), para Ciudad de México. No entanto, a singularidade dos processos indutores e das dinâmicas territoriais que impulsionam dá origem a formas e conteúdos que evocam uma categorização própria: a de arranjos urbano-regionais.

A visão geral desses arranjos, esboçada neste texto, deve ser aprofundada a cada caso para que possa apreender a especificidade de suas lógicas e interferências no processo de organização e gestão do território. Desde já, pode-se afirmar que o papel da aglomeração na economia e na indústria dos arranjos analisados leva à ampliação de sua dinâmica diferenciada. Papel que se reforça pela ação do Estado na formulação de políticas localizadas e realização de investimentos, como também pelas externalidades de densidade urbana, de atividades, infraestrutura, conhecimento e inovação, e pela proximidade geográfica e organizacional. Pode-se inferir, também, que os AURs tendem a reforçar a concentração regional, acompanhando a tendência mundial de fortalecimento às localidades mais servidas aos requisitos da economia global.

Tais arranjos mostram um evento que não é novo, que faz parte de uma fase mais recente do processo de metropolização, moldado por elementos históricos e naturais, sob processos políticos repletos de ideologias. Mas, no evento, há elementos novos, ideologizados e obscurecidos pela ideia de que são apenas dinâmicas que se reproduzem. Esses elementos e mesmo as dinâmicas, com suas novas interfaces 
e sua multiplicidade escalar, instigam discussão posta por De Mattos (1999), de que muito do que existia se esvai no horizonte de transformações céleres da globalização. Sob o risco de perdê-los no horizonte da memória, concorda-se, pois, com a citação de Aglieta (1979, p. 4), que afirma: "Hablar de reproducción es mostrar los procesos que permiten que lo que existe siga existiendo. En un sistema en que las relaciones internas se transforman, no todo sigue existiendo. Es necesario, por lo tanto, estudiar el modo en que surge lo nuevo en el sistema”.

Mantidas as lógicas e as dinâmicas em curso, sustentadas em estratégias de desenvolvimento regional fragilizadas (ou pactuadas) por uma condução majoritariamente corporativa na produção do espaço, pode-se vislumbrar que são ínfimas (ou inexistentes) as possibilidades de reversão do processo. Mesmo sob um cenário de reestruturação produtiva e reorganização espacial do capital, as novas centralidades concentradoras que se delineiam em território nacional — como produtos ou possibilidades a esse processo - reproduzem o mesmo perfil, no qual os indicadores de ótimo desempenho econômico, social e institucional não refletem processos capazes de impulsionar a inserção dos municípios adjacentes. Dessa forma, permanecendo o modelo de produção e de apropriação da riqueza gerada, as tendências são de que se sustentarão as mesmas lógicas e resultados, acentuando os traços atuais dos arranjos expandidos multidirecionalmente, ainda mais concentradores e desiguais.

Assim, torna-se necessária a discussão de alternativas de mudança do curso dos processos, com base em estratégias e políticas de desenvolvimento, como as que defendem o reforço à polinucleação, com a definição de macro e mesopolos estratégicos para o reordenamento do território, como medida de desconcentração das áreas de maior densidade do país (BRASIL, 2008). Alternativas como essa requerem o resgate do papel do Estado como formulador e implementador de políticas territoriais e uma profunda compreensão da natureza do fenômeno urbano-regional, de sua origem e da multiplicidade de escalas que interagem em sua órbita, para que se possam trabalhar hipóteses de transformação e possibilidades de reversão de dinâmicas e resultados. OEURE

\section{Referencias bibliográficas}

Aglietta, M. (1979). Regulación y crisis del capitalismo. Madrid: Siglo XXI de España Editores, apud De Mattos (1999).

Aguilar, A. G. (2002). Las mega-ciudades y las periferias expandidas: ampliando el concepto en Ciudad de México. EURE (Santiago), 28(85), 121-149.

Alonso, J. A. F. (2004). Efeitos da reestruturação produtiva na dinâmica da Região Metropolitana de Porto Alegre (RMPA) na década de 90. In Desigualdades socioespaciais na Região Metropolitana de Porto Alegre. Porto Alegre: Fundação de Economia e Estatística (FEE)/Núcleo de Estudos Regionais e Urbanos. (1 CD-ROM).

Anselin, L. (1995). Local indicators of spatial association (LISA). Geographical Analysis (Columbus, Ohio), 27(2), 94-115. 
Ascher, F. (1995). Metápolis ou l'avenir des villes. Paris: Ed. Odile Jacob.

Azzoni, C. R. (1986). Indústria e reversão da polarização no Brasil. Serie Ensaios Econômicos, n. 58. São Paulo: Instituto de Pesquisas Econômicas, Universidade de São Paulo (IPE/USP).

Benko, G. (2002). Mundialização da economia, metropolização do mundo. Revista do Departamento de Geografia da USP (São Paulo), n. ${ }^{\circ}$ 15, 45-54.

Benko, G.; Lipietz, A. (Org.). (1994). As regiōes ganhadoras: distritos e redes, os novos paradigmas da Geografia Econômica. Oeiras (Portugal): Celta Ed.

Borja, J; Castells, M. (1997). Local y global: la gestión de las ciudades en la era de la información. Madrid: Taurus, Pensamiento.

Brandão, C. A. (2007). Território \& desenvolvimento: as múltiplas escalas entre o local e o global. Campinas: Ed. da Universidade Estadual de Campinas (Unicamp).

Brasil (2008). Ministério do Planejamento, Orçamento e Gestão. Secretaria de Planejamento e Investimentos Estratégicos (SPI). Estudo da dimensão territorial para o planejamento: III. Regiões de referência. Brasília: MP/SPI. (5 v.).

Castello Branco, M. L. G. (2003). Espaços urbanos: uma proposta para o Brasil. Rio de Janeiro: Instituto Brasileiro de Geografia e Estatística (IBGE).

Castells, M. (2000). A questão urbana. São Paulo: Paz e Terra.

Ciccolella, P. (1998). Transformaciones macroeconómicas en la Argentina y reestructuración territorial en la Región Metropolitana de Buenos Aires. In C. A. de Mattos, D. Hiernaux-Nicolas, R. Botero (Comps.), Globalización y territorio. Impactos y perspectivas. Santiago: Pontificia Universidad Católica de Chile/Instituto de Estudios Urbanos, Fondo de Cultura Económica.

Consejo Nacional de Población (Conapo, México). (2007). Delimitación de las zonas metropolitanas de México 2005. México D.F.: Secretaría de Desarrollo Social, Consejo Nacional de Población; Instituto Nacional de Estadística, Geografía e Informática.

Cunha, I. J. (2001). Dinâmica demográfica e desenvolvimento industrial em Santa Catarina. In C. Siebert (Org.), Desenvolvimento regional em Santa Catarina. Blumenau: Edifurb.

Davidovich, F. (2001). Metrópole e território: metropolização do espaço no Rio de Janeiro. Encuentro de Geógrafos de América Latina, 8. Anais... Santiago, pp. 499--505 (1 CD-ROM). También en Cadernos Metrópole, n. ${ }^{\circ}$ 6, 67-77.

Davis, M. (2004). Planet of slums. New Left Review (London), 26(mar.-abr.), 5-34.

De Mattos, C. A. (1999). Santiago de Chile, globalización y expansión metropolitana: lo que existía sigue existiendo. EURE (Santiago), 25(76), 29-56. doi: 10.4067/S0250-71611999007600002.

De Mattos, C. A. (2002). Transformación de las ciudades latinoamericanas. ¿ Impactos de la globalización? EURE (Santiago), 28(85), 5-10.

De Mattos, C. A. (2004). Redes, nodos e cidades: transformação da metrópole latino-americana. In L. C. Q. Ribeiro (Org.), Metrópoles: entre a coesão e a fragmentação, a cooperação e o conflito. São Paulo: Fundação Perseu Abramo; Rio de Janeiro: Federação de Órgãos para a Assistência Social e Educacional (FASE).

De Mattos, C. A. (2005). Crescimento metropolitano na América Latina: Los Angeles como referência? In C. C. Diniz, M. B. Lemos, Economia e Território. Belo Horizonte: Ed. da Universidade Federal de Minas Gerais (UFMG).

De Mattos, C. A. (2010). Globalización y metamorfosis metropolitana en América Latina. De la ciudad 
a lo urbano generalizado (Documento de trabajo no 8). Madrid: Grupo de Estudios sobre Desarrollo Urbano (Gedeur).

Dematteis, G. (1998). Suburbanización y periurbanización: ciudades anglosajonas y ciudades latinas. In F. J. Monclus, (Ed.), La ciudad dispersa: suburbanización y nuevas periferias. Barcelona: Centre de Cultura Contemporánia de Barcelona.

Diniz, C. C.; Campolina, B. (2007). A região metropolitana de São Paulo: reestruturação, re-espacialização e novas funções. EURE (Santiago), 33(98), 27-43.

Empresa Paulista de Planejamento Metropolitano, S.A. (Emplasa). (1999). Complexo Metropolitano Expandido. Disponível em: <http://www.emplasa.sp.gov.br/portalemplasa/Linha_do_ Tempo/LinhadoTempo_1999.asp>. Acesso em: out. 2008.

Fujita, M.; Krugman, P.; Venables, A. (1999). The spatial economy. Cambridge: The MIT Press.

González, S. (2008). Las narrativas escalares de la globalización. Coloquio Dinámicas urbanas y regionales desde la perspectiva de las escalas. In Congreso Nacional sobre Problemáticas Sociales Contemporáneas, 5. Universidad Nacional del Litoral. Santa Fe, Argentina, oct. 2008. (Não publicado).

Gottman, J. (1970). A urbanização e a paisagem americana: o conceito de megalópole. In S. B. Cohen, (Org.), Geografia humana nos Estados Unidos. Rio de Janeiro: Fórum (Estante de Ciências Sociais).

Haddad, M. B. (2010). Eixo Goiânia-Anápolis-Brasília: estruturação, ruptura e retomada das políticas públicas. Seminário Nacional Governança Urbana e Desenvolvimento Metropolitano. Observatório das Metrópoles, Anais... Natal, setembro 2010 (1 CD-ROM).

Hiernaux-Nicolas, D. (1998). Reestructuración económica y cambios territoriales en México. Un balance 1982-1995. In C. A. De Mattos, D. Hiernaux-Nicolas, D. R. Botero (Comps.), Globalización y territorio: impactos y perspectivas. Santiago: Pontificia Universidad Católica de Chile/Instituto de Estudios Urbanos, Fondo de Cultura Económica.

Hiernaux-Nicolas, D. (1999). Los frutos amargos de la globalización: expansión y reestructuración metropolitana de la ciudad de México. EURE (Santiago), 25(76), 57-78. doi: 10.4067/ S0250-71611999007600003.

Indovina, F. (1990). La cittá diffusa. Venezia: Daest (Dipartimento di Analisi Economica e Sociale del Território) Ed.

Instituto Brasileiro de Geografia e Estatística (IBGE). (2008). Regiões de influência das cidades 2007. Rio de Janeiro: Autor.

Instituto de Pesquisa Econômica Aplicada (IPEA). (2002). Configuração atual e tendências da rede urbana do Brasil. Série Caracterização e Tendências da Rede Urbana do Brasil, 1. Brasília: IPEA. Convênio IPEA, IBGE, UNICAMP/IE/NESUR.

Instituto Paranaense de Desenvolvimento Econômico e Social (Ipardes) (2000). Redes urbanas regionais: Sul. Série Caracterização e Tendências da Rede Urbana do Brasil, 6. Brasília: Instituto de Pesquisa Econômica Aplicada (IPEA). Convênio IPEA, IBGE, UNICAMP/IE/NESUR, IPARDES.

Laurelli, E.; Montaña, E.; Schweitzer, A. (1998). El despliegue territorial de la reestructuración económica y los procesos de integración. Buenos Aires y Mendoza: dos metrópolis en la disputa por la hegemonía regional y su inserción en un contexto de exclusión. In C. A. de Mattos, D. Hiernaux-Nicolas, D. R. Botero (Comps.), Globalización y Territorio: impactos y perspec- 
tivas. Santiago: Pontificia Universidad Católica de Chile/Instituto de Estudios Urbanos, Fondo de Cultura Económica.

Lefebvre, H. (1991). O direito à cidade. São Paulo: Ed. Moraes.

Leme, H. J. de C. (2003). A espacialidade do desenvolvimento: as cidades da Região Centro-Oeste. In M. F. Gonçalves, C. A. Brandão, A. C. F. Galvão (Orgs.), Regióes e cidades, cidades nas regióes: o desafio urbano-regional. São Paulo: Ed. da Universidad Estadual Paulista (Unesp) / Associação Nacional de Pós-Graduação e Pesquisa em Planejamento Urbano e Regional (Anpur).

Lemos, M. B.; Moro, S.; Domingues, E. P.; Ruiz, R. M. (2005). A organização territorial da indústria no Brasil. In J. A. de Negri, M. S. Salerno (Orgs.), Inovações, padrões tecnológicos e desempenho das firmas industriais brasileiras. Brasília: Instituto de Pesquisa Econômica Aplicada (IPEA).

Lencioni, S. (2003a). A emergência de um novo fato urbano de caráter metropolitano em São Paulo. A particularidade de seu conteúdo sócio-espacial, seus limites regionais e sua interpretação teórica. Encontro Nacional da Anpur, 10. Belo Horizonte. Anais... Belo Horizonte: Associação Nacional de Pós-Graduação e Pesquisa em Planejamento Urbano e Regional (Anpur), maio 2003. (1 CD-ROM).

Lencioni, S. (2003b). Cisão territorial da indústria e integração regional no Estado de São Paulo. In M. F. Gonçalves, C. A. Brandão, A. C. F. Galvão (Orgs.), Regiôes e cidades, cidades nas regióes: o desafio urbano-regional. São Paulo: Ed. da Universidad Estadual Paulista (Unesp) / Associação Nacional de Pós-Graduação e Pesquisa em Planejamento Urbano e Regional (Anpur).

Lencioni, S. (2006). Da cidade e sua região à cidade-região. In J. B. da Silva, L. C. Lima, D. Elias (Orgs.), Panorama da geografia brasileira. São Paulo: Annablume.

Leroy, S. (2000). Sémantiques de la métropolisation. L'Espace géographique (Montpellier: Éditions Belin), n. ${ }^{\circ} 1,78-86$.

Limonad, E. (2007). No todo acaba en Los Ángeles. ¿Un nuevo paradigma: entre la urbanización concentrada y dispersa? Biblio 3W. Revista Bibliográfica de Geografia y Ciencias Sociales (Serie documental de Geo Crítica), 12(734). Disponível em: <http://www.ub.es/geocrit/ b3w-734.htm>. Acesso: ago. 2008.

Lins, H. de G. (2000). A ação governamental. In. Instituto Geográfico de Santa Catarina, A realidade catarinense no século $X X$. Florianópolis: Instituto Geográfico de Santa Catarina.

Meyer, R. M. P.; Grostein, M. D.; Biderman, C. (2004). São Paulo Metrópole. São Paulo: Editora da Universidade de São Paulo (Edusp), Imprensa Oficial.

Monclús, F. J. (1998). Suburbanización y nuevas periferias. Perspectivas geográfico-urbanísticas. In F. J. Monclús (Ed.), La ciudad dispersa. Barcelona: Centro de Cultura Contemporânea de Barcelona.

Monclús, F. J. (1999). Ciudad dispersa y ciudad compacta. Perspectivas urbanísticas sobre las ciudades mediterráneas. D'Humanitats (Girona), n. ${ }^{\circ}$ 7, p. 95-110.

Moro, S.; Lemos, M. B.; Domingues, E. P.; Ruiz, R. M.; Freitas, F. (2006). A dimensão espacial do potencial exportador das firmas industriais brasileiras. In J. A. de Negri, B. C. Araújo (Orgs.), As empresas brasileiras e o comércio internacional. Brasília: Instituto de Pesquisa Econômica Aplicada (Ipea). 
Moura, R. (2009). Arranjos urbano-regionais no Brasil: uma análise com foco em Curitiba. Tese (Doutorado em Geografia), Universidade Federal do Paraná, Curitiba.

Percqueur, B.; Zimmermann, J. B. (2005). Fundamentos de uma economia da proximidade. In C. C. Diniz, M. B. Lemos (Orgs.), Economia e Território. Belo Horizonte: Ed. da Universidade Federal de Minas Gerais (UFMG).

Ribeiro, L. C. de Q. (2009). Hierarquização e identificação dos espaços urbanos. Rio de Janeiro: Letra Capital, Observatório das Metrópoles.

Ruiz, R. M.; Pereira, F. B. (2008). Estrutura e dinâmica espaço-temporal das metrópoles brasileiras. Áreas de Polarização das Aglomerações Populacionais e Econômicas. Relatório de Pesquisa apresentado ao Observatório das Metrópoles/Projeto Instituto do Milênio-CNPq, novembro. Disponível em: <http://observatoriodasmetropoles.net/index.php?option=com_chronocont act\&chronoformname $=$ receberarquivo\&arquivo=produtos $/$ Geubs-E-Mapas-Download. pdf>. Acesso: out. 2008.

Santos, M. (1996). Técnica, espaço, tempo: globalização e meio técnico-cientifico informacional. São Paulo: Hucitec.

Santos, M.; Silveira, M. L. (2001). O Brasil: território e sociedade no início do século XXI (2a ed.). Rio de Janeiro: Record.

São Paulo. (1976). Secretaria de Economia e Planejamento. Politica de Desenvolvimento Urbano e Regional. São Paulo: SEP.

Sassen, S. (1998). As cidades na economia global. Megalópolis. São Paulo: Studio Nobel.

Sassen, S. (2007). El reposicionamiento de las ciudades y regiones urbanas en una economía global: ampliando las opciones de políticas y gobernanza. EURE (Santiago), 33(100), 9-34.

Schweitzer, M. (2008). El ferrocarril y su contribución a la integración territorial. Transporte inclusivo y transporte selectivo. Territorios conectados, territorios excluidos. Colóquio de Transformaçôes Territoriais, 7. Anais... Curitiba: Universidade Federal do Paraná (UFPR), setembro.

Scott, A. J. (1994). A economia metropolitana. In G.Benko, A. Lipietz (Orgs.), As regiöes ganhadoras: distritos e redes, os novos paradigmas da Geografia Econômica. Oeiras (Portugal): Celta Ed.

Scott, A. J.; Agnew, J.; Soja, E. W.; Storper, M. (2001). Cidades-regiões globais. Espaço e Debates (São Paulo), $n^{\circ} 41,11-25$.

Siebert, C. (2009). A rede urbana de Santa Catarina: abordagem transescalar. Encontro Nacional da Anpur, 13. Florianópolis. Anais... Florianópolis: Associação Nacional de Pós-Graduação e Pesquisa em Planejamento Urbano e Regional (Anpur), maio 2009. (1 CD-ROM).

Soja, E. W. (2002). Postmetropolis: Critical studies of cities and regions. Oxford: Blackwell Publishing. Storper, M.; Venables, A. J. (2005). O burburinho: a força econômica da cidade. In C. C. Diniz, M. B. Lemos (Orgs.), Economia e Território. Belo Horizonte: Ed. da Universidade Federal de Minas Gerais (UFMG).

Unikel, L.; Ruiz, C.; Garza, G. (1978). El desarrollo urbano de México. México: El Colegio de México. Viard, J. (1994). La societé dárchipel ou les territoires du village global. Paris: Ed. de l'Aube, apud Lencioni (2006).

Villareal, D. R. (1998). Proceso de reestructuración industrial y efectos en el área metropolitana de Monterrey, Nuevo León, México. In C. A. de Mattos, D. Hiernaux-Nicolas, D. R. Botero (Comps.), Globalización y territorio: impactos y perspectivas. Santiago: Pontificia Universidad Católica de Chile/Instituto de Estudios Urbanos, Fondo de Cultura Económica. 